\title{
MONTAGEM DE UM SISTEMA PARA MEDIDAS GALVANOSTÁTICAS SIMULTÂNEAS EM MAIS DE UMA
}

\section{CÉLULA}

Victor Solymossy e Ernesto Chaves Pereira*

Departamento de Química, Universidade Federal de São Carlos, CP 676, 13560-970 São Carlos - SP, Brasil

Ailton José Terezo

Departamento de Física, Universidade Federal do Mato Grosso, Av. Fernando Correa da Costa, s/n, 78060-900 Cuiabá - MT, Brasil

Recebido em 18/1/06; aceito em 18/10/06; publicado na web em 14/5/07

\begin{abstract}
THE CONSTRUCTION OF A MULTI-CELL GALVANOSTATIC EQUIPMENT FOR ACCELERATED STABILITY ELECTRODE TEST. The present work deals with the design and construction of an equipment for muti-cell accelerated stability test measurements (AST) of dimensionally stable anodes (DSA). The equipment was built using only components that were available in the laboratory. Measurements of three electrochemical cells can be performed using the developed software. The acquisition time interval and the cut-off potencial can be set by the user. Experimental data for $\mathrm{RuO}_{2}$ electrodes obtained with the built equipment are in agreement with the literature.
\end{abstract}

Keywords: accelerated stability test; multi-cell; equipment design.

\section{INTRODUÇÃO}

Os anodos dimensionalmente estáveis (ADEs) são materiais utilizados, principalmente, na produção de cloro e soda cáustica, bem como em alguns outros processos eletroquímicos industriais que envolvem a reação de desprendimento de oxigênio no anodo ${ }^{1}$.

Ao se objetivar o desenvolvimento de ADEs para uso em indústria, alguns fatores, como custo do eletrodo preparado, eficiência e durabilidade no processo de interesse, devem ser levados em consideração. Todavia, o custo do eletrodo pode ser entendido não apenas como o custo envolvido em sua fabricação, mas também como uma relação entre custo de fabricação e tempo que ele permanecerá adequado naquele processo.

Em escala de laboratório, para se estimar o tempo de vida útil de um ADE, uma das técnicas utilizadas é o teste de estabilidade acelerada (TEA). Tal técnica baseia-se no monitoramento da diferença de potencial entre o eletrodo de trabalho (ET) e um de referência (ER) em função do tempo quando aplicada uma corrente constante entre o eletrodo de trabalho e um contra-eletrodo $(\mathrm{CE})^{2}$. $O$ final do TEA ocorre quando o potencial do eletrodo de trabalho atinge um valor pré-determinado, normalmente $6 \mathrm{~V}$ (contra o eletrodo de referência) ${ }^{3}$. Conforme o material utilizado e as condições experimentais, tais testes podem durar centenas de horas.

Existem atualmente potenciostatos e galvanostatos comerciais que podem ser utilizados para se realizar os TEAs. Todavia, conforme já mencionado, tais testes podem levar até centenas de horas para serem concluídos, restringindo a utilização de um equipamento versátil, como um potenciostato, para uma aplicação relativamente simples. Por este motivo, o presente trabalho propõe a construção de um sistema para teste de estabilidade acelerada de eletrodos em mais de uma célula eletroquímica simultaneamente, utilizando apenas equipamentos de baixo custo e que se encontravam à disposição no laboratório.

*e-mail: decp@power.ufscar.br

\section{PARTE EXPERIMENTAL}

\section{Preparação dos eletrodos}

Os eletrodos foram preparados utilizando-se placas de titânio de 10 x 10 x 0,5 mm como suporte (TiBrasil 99,7\%). Os suportes foram tratados com um jateamento de areia seguido de tratamento químico com $\mathrm{HCl}$ concentrado à quente por 30 min e solução de ácido oxálico $10 \%(\mathrm{~m} / \mathrm{m})$ à quente por $30 \mathrm{~min}$. Ao término do tratamento químico, os suportes foram lavados com água desionizada e secos a $130{ }^{\circ} \mathrm{C}$.

A solução precursora do óxido foi preparada dissolvendo-se ácido cítrico (AC) (Synth) em etileno glicol (EG) (Merck) a $60^{\circ} \mathrm{C}$. A esta solução foi adicionado $\mathrm{RuCl}_{3} .3 \mathrm{H}_{2} \mathrm{O}$ (Fluka) na proporção molar AC:EG:Ru de 1:4,65:0,33. A solução precursora foi aplicada no suporte por pincelamento e o material foi submetido a tratamento térmico a $130{ }^{\circ} \mathrm{C}$ por $30 \mathrm{~min}$, seguido de aquecimento a 250 ${ }^{\circ} \mathrm{C}$ por $10 \mathrm{~min}$ a fim de aumentar a aderência da cobertura ao suporte. Finalmente, o material foi submetido à calcinação em 450 ${ }^{\circ} \mathrm{C}$ por 5 min para eliminar toda a matéria orgânica e formar o óxido. Este procedimento foi repedido 10 vezes, originando uma camada de óxido de $2,2 \pm 0,2 \mathrm{mg} \mathrm{cm}^{-2}$ nos eletrodos.

As células eletroquímicas utilizadas e a conexão entre as mesmas estão ilustradas na Figura 1. Como pode ser observado, as células são conectadas em série, de tal forma que o contra eletrodo

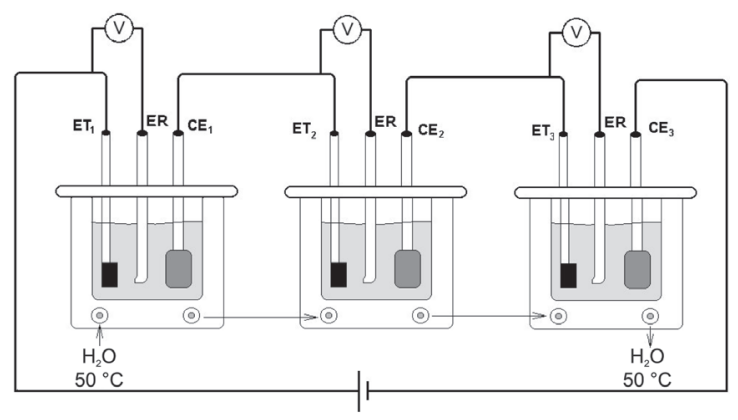

Figura 1. Ilustração das células eletroquímicas utilizadas 
da célula 1 está conectado com o eletrodo de trabalho da célula 2. As medidas de potencial são realizadas utilizando-se os multímetros conectados entre o eletrodo de trabalho e o de referência. O eletrodo de trabalho foi construído conforme descrito acima. O contra eletrodo utilizado foi uma placa de platina com área superficial geométrica de $1 \mathrm{~cm}^{2}$. Como eletrodo de referência foi utilizado um eletrodo de calomelano saturado em $\mathrm{NaCl}$ (ECS). As medidas foram realizadas em solução aquosa de ácido perclórico $1 \mathrm{M}$ como eletrólito. A célula eletroquímica foi mantida à $50^{\circ} \mathrm{C}$ e a densidade de corrente utilizada foi de $0,8 \mathrm{~A} \mathrm{~cm}^{-2}$. O tempo entre a aquisição de dois dados de uma célula foi de $10 \mathrm{~s}$.

\section{EQUIPAMENTO}

O equipamento foi construído para a medida em três células eletroquímicas simultaneamente. Para tal, foram utilizados dois multímetros HP $34401 \mathrm{~A}^{4}$ e um multímetro Keithley $195 \mathrm{~A}^{5}$; uma fonte Keithley $228 \mathrm{~A}^{6}$ como fonte de corrente; uma placa de interface HPIB PCI conectada a um microcomputador com processador Pentium $200 \mathrm{MHz}$. O software para aquisição de dados foi desenvolvido na linguagem HPVEE, versão 5.0 (Hewlett-Packard) ${ }^{7,8}$. É importante salientar que foram utilizados equipamentos disponíveis no laboratório, para diminuir o custo. $\mathrm{O}$ mesmo tipo de equipamento poderia ter sido construído com qualquer fonte de corrente estabilizada existente no mercado e medidos os potenciais de $n$ células, utilizando-se uma placa $\mathrm{AD}$ de $n$ canais diferenciais.

O programa desenvolvido, cujo fluxograma simplificado encontra-se na Figura 2, faz a aquisição dos dados em intervalos pré-determinados pelo usuário, em até três células eletroquímicas de maneira independente, isto é, cada célula é lida separadamente. Uma condição de potencial igual ou superior a $6 \mathrm{~V}$ determina o final do experimento para cada uma das três células. Caso uma ou mais células atinja a condição limite, o programa emite um aviso, sonoro e visual, dando ao operador tempo necessário para encerrar o experimento naquela célula sem afetar as demais. É possível também substituir uma célula sem a necessidade de interromper o experimento nas demais, uma vez que utilizamos um sistema de chaveamento com interruptores do tipo $\mathrm{HH}$, ilustrado na Figura 3, que permite causar um curto-circuito em cada uma das células de maneira independente. Se o operador não interromper o experimento, o programa interrompe todas as células a fim de evitar uma sobrecarga na fonte.

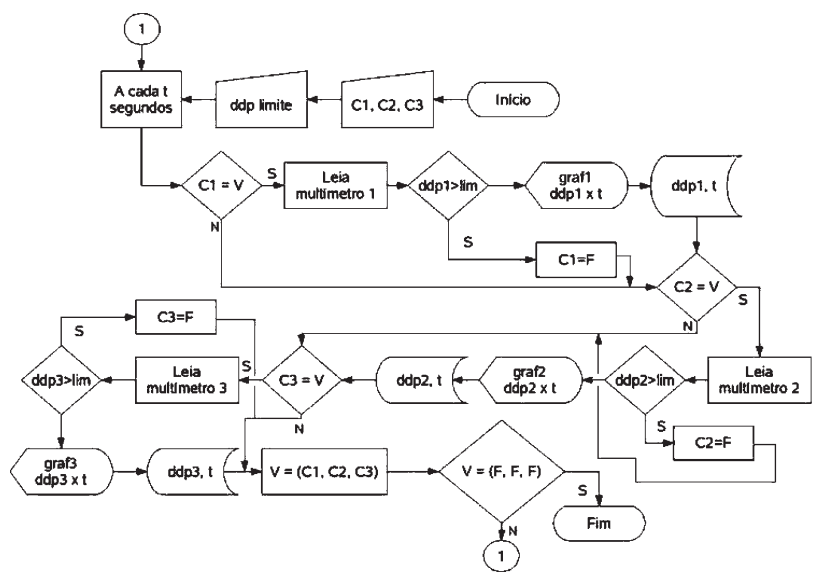

Figura 2. Fluxograma simplificado de funcionamento do programa para aquisição de dados

\section{RESULTADOS E DISCUSSÃO}

Testes de estabilidade acelerada foram realizados com eletrodos semelhantes entre si, no equipamento montado. Na Figura 4, é apre-

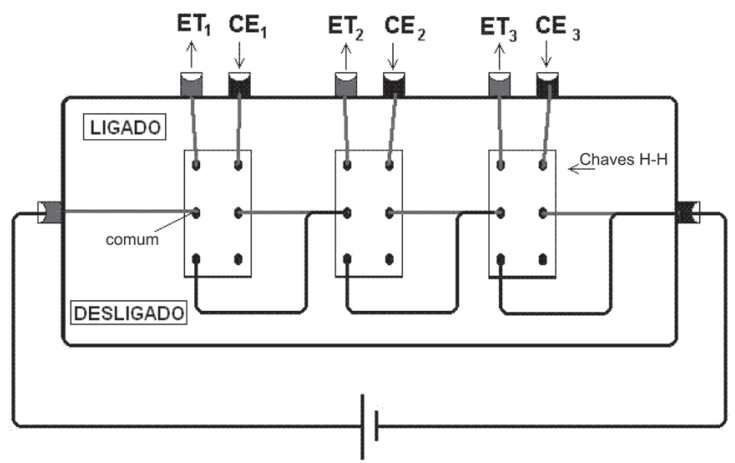

Figura 3. Esquema de montagem das chaves $H H$, com os eletrodos em série

sentado um cronopotenciograma com o perfil de um dado medido para o eletrodo descrito na parte experimental. O resultado obtido é típico para TEA de eletrodo de $\mathrm{RuO}_{2}{ }^{3}$. É importante ressaltar que o experimento foi propositalmente interrompido pelo experimentador após aproximadamente $35 \mathrm{~h}$ e, posteriormente, retomado, justificando a existência de uma descontinuidade da curva nesta região. Este comportamento também é típico para TEA de ADEs.

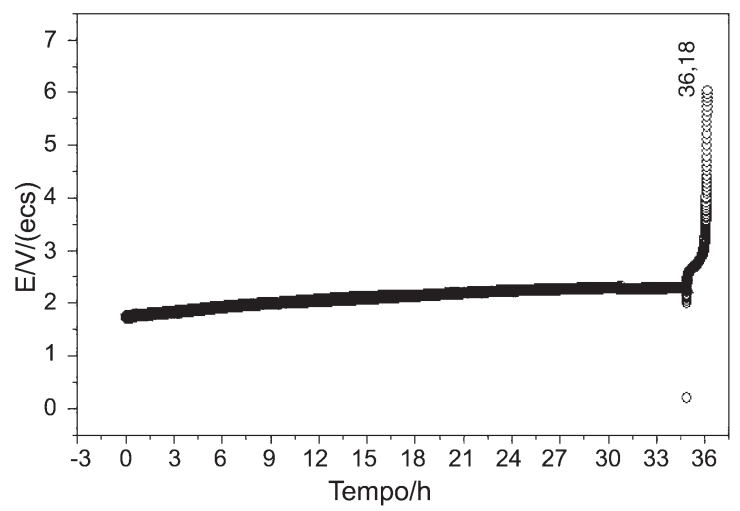

Figura 4. Cronopotenciograma para um mesmo tipo de eletrodo utilizando o equipamento construído

\section{CONCLUSÕES}

A partir dos testes efetuados, pode-se concluir que o sistema construído pode substituir com vantagens os equipamentos utilizados habitualmente para realização de experimentos de teste de estabilidade acelerada, uma vez que o custo de montagem (ou aquisição) é baixo e existe a possibilidade de se testar mais de um eletrodo simultaneamente e de maneira independente.

O sistema montado pode ser facilmente adaptado para sua utilização também para ciclos de carga e descarga de baterias, utilizando inversão de potencial por chaveamento automático nas células.

\section{REFERÊNCIAS}

1. Bockris, J. O. M.; Minvski, Z. S.; Electrochim. Acta 1976, 21, 1115.

2. Loucka, T.; J. Appl. Electrochem. 1981, 11, 143.

3. Terezo, A. J.; Pereira, E. C.; Mater. Lett. 2002, 53, 339.

4. HP 34401A Multimeter User's Guide; $2^{\text {nd }}$ ed., Hewlett-Packard Company: Palo Alto, 1996.

5. Model 195A Digital Multimeter Instruction Manual; Keithley Instruments Inc.: Cleveland, 1984.

6. Model 228A Voltage/Current Source Instruction Manual; Keithley Instruments Inc.: Cleveland, 1988.

7. HP VEE Advanced Programming Techniques; $4^{\text {th }}$ ed., Hewlett-Packard Company: Palo Alto, 1998.

8. HP Standard Instrument Control Library; $5^{\text {th }}$ ed., Hewlett-Packard Company: Palo Alto, 1998. 